
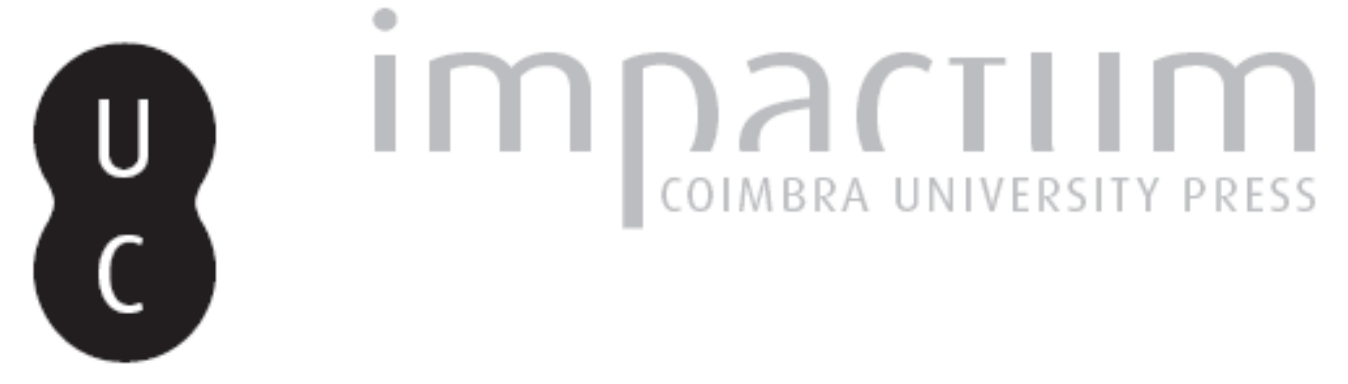

\title{
A visão do Outro nas Cartas de Itália de Lopo de Almeida
}

Autor(es): $\quad$ Lopes, Paulo Esmeraldo Catarino

Publicado por: Centro de História da Sociedade e da Cultura

URL persistente:

URI:http://hdl.handle.net/10316.2/39479

DOI:

DOI:http://dx.doi.org/10.14195/1645-2259_11_5

Accessed : $\quad$ 26-Apr-2023 12:29:53

A navegação consulta e descarregamento dos títulos inseridos nas Bibliotecas Digitais UC Digitalis, UC Pombalina e UC Impactum, pressupõem a aceitação plena e sem reservas dos Termos e Condições de Uso destas Bibliotecas Digitais, disponíveis em https://digitalis.uc.pt/pt-pt/termos.

Conforme exposto nos referidos Termos e Condições de Uso, o descarregamento de títulos de acesso restrito requer uma licença válida de autorização devendo o utilizador aceder ao(s) documento(s) a partir de um endereço de IP da instituição detentora da supramencionada licença.

Ao utilizador é apenas permitido o descarregamento para uso pessoal, pelo que o emprego do(s) título(s) descarregado(s) para outro fim, designadamente comercial, carece de autorização do respetivo autor ou editor da obra.

Na medida em que todas as obras da UC Digitalis se encontram protegidas pelo Código do Direito de Autor e Direitos Conexos e demais legislação aplicável, toda a cópia, parcial ou total, deste documento, nos casos em que é legalmente admitida, deverá conter ou fazer-se acompanhar por este aviso.

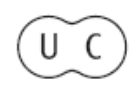




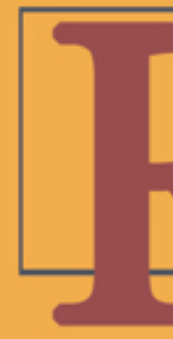

\section{evista de História} da Sociedade e da Cultura

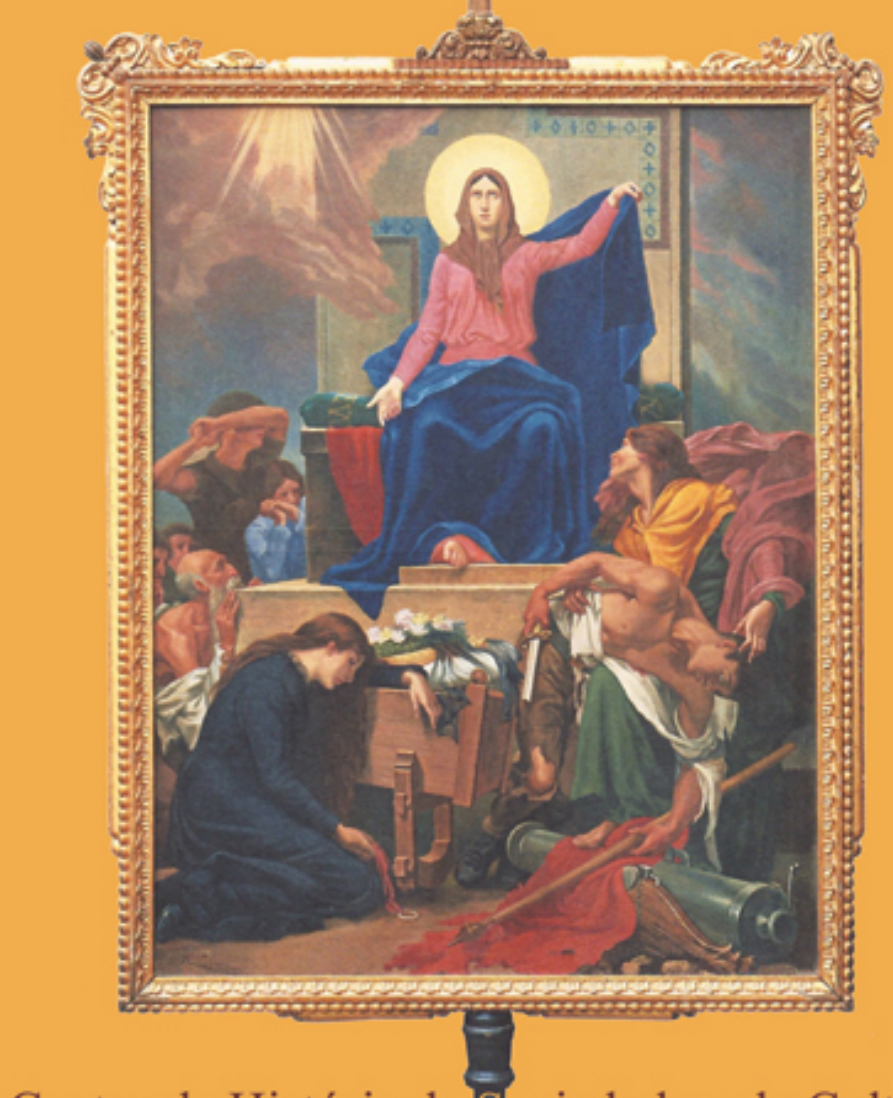

Centro de História da Sociedade e da Cultura Universidade de Coimbra 


\title{
A visão do Outro nas Cartas de Itália de Lopo de Almeida
}

\author{
Paulo Esmeraldo Catarino Lopes \\ Instituto de Estudos Medievais \\ Texto recebido em/ Text submitted on: 20/01/2011 \\ Texto aprovado em/ Text approved on: 31/08/2011
}

\section{Resumo/Abstract:}

Em Novembro de 1451 partia de Portugal com destino a Itália a comitiva de acompanhamento da infanta D. Leonor, segunda filha de D. Duarte e irmã de D. Afonso V, para confirmação do seu casamento com o imperador Habsburgo Frederico III.

Notável iniciativa diplomática e ocasião única de afirmação e de internacionalização da monarquia portuguesa, este matrimónio resulta de um ambicioso projecto de $\mathrm{D}$. Afonso $\mathrm{V}$ que visa legitimar aos olhos das grandes potências internacionais uma dinastia que nascera pouco conforme com o direito sucessório.

Dirigiam a comitiva de acompanhamento João Fernandes da Silveira e Lopo de Almeida (primeiro conde de Abrantes), tendo este último enviado a $\mathrm{D}$. Afonso $\mathrm{V}$ quatro cartas em que dá notícia dos acontecimentos que marcaram a viagem, bem como da forma como a comitiva foi recebida. $\mathrm{O}$ facto de o embaixador concentrar toda a sua atenção na acção, bem como na descrição das cerimónias e do comportamento dos intervenientes, faz de tais registos epistolares uma fonte de inegável valor histórico-antropológico.

A visão e avaliação do Outro europeu é constante nas Cartas e opera-se sempre através de uma análise comparativa com os portugueses. Por outras palavras, os referentes culturais de Lopo de Almeida constituem-se como um código com base no qual o mesmo realiza a sua avaliação antropológica.

Sempre perspicaz, e não raras vezes irónico e satírico, Lopo de Almeida fornece retratos ora colectivos, como o dos alemães, ora individuais, como o do imperador Frederico III. De reter é que em caso algum estamos perante retratos frios. Ao contrário, são sempre representações extremamente ricas do ponto de vista do sentimento, da emoção e do elemento humano, inequivocamente aquele que mais entusiasma o autor da narrativa.

Em síntese, pelo seu conteúdo, mas também pelo contexto em que foram produzidas, as quatro cartas enviadas de Itália por Lopo de Almeida ao rei D. Afonso V constituem um testemunho privilegiado, por um lado, da forma como os portugueses olhavam o Outro europeu e, por outro lado, da forma como se olhavam a si próprios por reacção a esse mesmo Outro europeu, em meados do século XV.

In November 1451 departed from Portugal to Italy the accompaniment entourage of Eleanor, second daughter of King Duarte and sister of Afonso V, for confirmation of her marriage to the Habsburg Emperor Frederick III.

Notable diplomatic initiative and unique opportunity for affirmation and internationalization of the Portuguese monarchy, this marriage is the result of an ambitious project of King Afonso $\mathrm{V}$ which aims to legitimize in the eyes of the great international powers a dynasty that was born slightly according to the law of succession.

Headed the delegation Fernandes da Silveira and Lopo de Almeida (first count of Abrantes), the latter having sent to Afonso $\mathrm{V}$ four letters giving news of events that marked the journey as well as how the group was welcomed. The fact that the ambassador focus all 
their attention on the action and the description of the ceremonies and the players' behavior, makes such epistolary records a source of undeniable historical and anthropological value.

The vision and evaluation of the european Other is constant in the Letters and operates always through a comparative analysis with the Portuguese. In other words, the cultural references of Lopo de Almeida up as a code under which he performs his anthropological assessment.

Always insightful, and quite often ironic and satirical, Lopo de Almeida provides pictures sometimes collective, like the Germans, sometimes individual, such as the Emperor Frederick III. Of note is that in any case we are dealing with cold pictures. Instead, representations are always extremely rich in terms of feeling, emotion and the human element, one that most clearly excites the author of the narrative.

In summary, by its content but also by the context in which they were produced, the four letters sent from Italy by Lopo de Almeida to King Afonso V are a privileged witness, on one hand, of the portuguese way of looking at the european Other and, on the other hand, the way they looked at themselves by reaction to that same european Other in the mid-fifteenth century.

Palavras chave/Keywords:

Visão do Outro; Encontro civilizacional; Imperador Habsburgo Frederico III; Política de casamentos; Referentes culturais; Costumes cortesãos; Modelos de comportamento social.

Vision of the Other; Civilizational encounter; Habsburg Emperor Friedrich III; Political marriages; Cultural references; Courtiers manners; Models of social behavior. 
Não é apenas no contexto dos Descobrimentos que encontramos notáveis testemunhos relativos ao choque civilizacional resultante do encontro e do contacto com o Outro, tido como essencialmente diferente.

Com efeito, também nas estradas poeirentas da muito percorrida Europa, sobretudo quando em direcção aos espaços italianos, desenham-se contactos e vislumbram-se avaliações mútuas. Estas vias constituem o equivalente continental europeu às rotas atlânticas, e através delas os portugueses foram igualmente ao encontro de outros povos e outras culturas.

Palco de convergências e divergências políticas, sociais, económicas e culturais, o velho continente foi pois, fonte de preciosos registos acerca da alteridade entre europeus nos finais da Idade Média. Disto nos dão conta, de forma exemplar, as Cartas de Itália ${ }^{1}$ da autoria do embaixador Lopo de Almeida $^{2}$ (c. 1416-1508) e editadas contemporaneamente pelo investigador Rodrigues Lapa (1897-1989).

Em 12 de Novembro de 1451 partia de Portugal com destino a Itália, a comitiva de acompanhamento da infanta D. Leonor (1434-1467), segunda filha de D. Duarte (1391-1438) e irmã de D. Afonso V (1432-1481), para confirmação do seu casamento com o imperador Habsburgo Frederico III (1415-1493), já celebrado por contrato em Nápoles, em 10 de Dezembro do ano anterior ${ }^{3}$, e por procuração ${ }^{4}$ na corte portuguesa, em fins de Julho daquele ano: "Primeiramente, por disposição da divina graça, foi entre as referidas partes combinado, acordado e decidido que o matrimónio se faz e se há-de fazer e celebrar com pleno efeito pelo dito sereníssimo e poderosíssimo senhor rei dos Romanos com a dita inclitíssima

1 Vide Lopo de Almeida, Cartas de Itália, Rodrigues Lapa (ed.), Lisboa, Imprensa Nacional, 1935.

2 D. Lopo de Almeida foi o primeiro conde de Abrantes, título concedido por D. Afonso V, em 1476. Pertenceu ao Conselho Real e foi igualmente vedor da Fazenda do monarca, bem como mordomo-mor, contador-mor e escrivão da puridade da rainha D. Joana.

3 Cf. "Contrato de casamento entre o Imperador Frederico rei dos Romanos e a Infanta Dona Leonor de Portugal, irmã do rei Dom Afonso V de Portugal, feito pelo rei Dom Afonso de Aragão. Nápoles, 1450, Dezembro, 10." in Princesas de Portugal, Contratos Matrimoniais dos Séculos XV e XVI, Aires A. Nascimento (ed.) com a colaboração de Maria Filomena Andrade \& Maria Teresa Rebelo da Silva, Lisboa, Edições Cosmos, 1992, pp. 63-83.

4 Cf. "Carta de crença do imperador Frederico a D. Afonso V, na qual o informa que envia mestre Tiago Motz, e Nicolau de Valkenstein, ambos seus capelães, com procuração e poder bastante para receberem por sua esposa a infanta D. Leonor, irmã do mesmo D. Afonso V, Neustadt, 1451, Março, 14.", ibidem, pp. 85-87. 
e claríssima Infanta a donzela Dona Leonor por esta maneira: agora por palavras de futuro entre os ditos mandatários, procuradores e embaixadores de ambas as partes, e depois por palavras de presente, à face da Santa Madre Igreja, tal como ensinam e dispõem os preceitos canónicos e a disciplina da religião Cristã." "5 "Sereníssimo príncipe e irmão caríssimo. Enviamos a Vossa Serenidade os honrados mestres Tiago de Motz, bacharel de teologia sagrada, e Nicolau de Valkenstein, nossos dilectos e fiéis capelães, munidos de pleno mandato de procuração, a fim de que o matrimónio, a contrair na cidade de Nápoles, por embaixadores de uma e outra parte, entre nós e a ilustríssima Infanta Leonor de Portugal, vossa irmã, de momento por palavras de futuro, conforme contrato feito, pelos mesmos embaixadores, agora, em nossa vez e em nosso nome, com a dita ilustríssima Infanta, por palavras de presente, o contraiam e confirmem e finalmente por arras de anel e outras solenidades, para isso requeridas, para nós desposem como esposa legítima e aceitem como mulher, e façam todas e cada uma das outras coisas que entre os anteriormente citados embaixadores tenham sido concordadas e nos instrumentos e cartas, antes realizados, se contém mais completamente e nas nossas cartas de procuração e mandato, claramente está expresso."6

Notável (porque plena de êxito) iniciativa ao nível da diplomacia internacional, o dito matrimónio resulta, afinal, de um ousado e ambicioso projecto político encetado por $\mathrm{D}$. Afonso $\mathrm{V}$, que visava sentar no trono do Sacro Império Romano-Germânico, logo em 1451, uma portuguesa, D. Leonor, e no trono castelhano-leonês, em 1455, sua irmã, a rainha D. Joana de Portugal (1439-1475).

Como o investigador Luís Miguel Duarte assinala, o matrimónio de um membro da casa real não acontece por "motivos do coração", ou seja, por motivos pessoais e particulares, mas antes por interesse do país e do reino. Daí, inevitavelmente, constituir uma questão eminentemente pública ${ }^{7}$.

Neste quadro político-mental, os descendentes, em especial as filhas, eram vistos como um investimento e o seu casamento "era rigorosamente assunto de Estado. Fazia-se e desfazia-se com a mesma volatilidade de

5 "Contrato de casamento entre o Imperador Frederico rei dos Romanos e a Infanta Dona Leonor de Portugal....", op. cit., p. 67.

6 "Carta de crença do imperador Frederico a D. Afonso V...", op. cit., p. 85.

7 Cf. Luís Miguel Duarte, D. Duarte, Rio de Mouro, Temas e Debates, 2007, pp. 128-175. 
qualquer tratado diplomático; mudando as alianças, mudavam os contratos matrimoniais." Inclusive nos contratos e respectivas cláusulas matrimoniais (bem como nas negociações que os antecedem), o que surge à cabeça são as dimensões política e patrimonial.

Nesta medida, os próprios nubentes viam o matrimónio como uma das "muitas obrigações do seu ofício, com dois propósitos claros: estabelecer ou cimentar alianças e produzir sucessores."

Verdade tanto maior tratando-se de D. Afonso V que, tal como o avô e o pai, em particular este último, encarava com o maior rigor e seriedade todos os movimentos que de alguma forma pudessem contribuir para fortalecer a imagem do país, da família real e do monarca.

É este, com efeito, o contexto histórico-político que leva ao casamento de D. Leonor com o imperador Frederico III. Havia que legitimar uma dinastia que nascera pouco conforme com o direito sucessório.

Dito de outro modo, a chegada ao poder da casa de Avis fora polémica e até pouco convincente. Impunha-se, pois, como prioritário assentar o seu governo em bases realmente sólidas, porque fortalecidas (e reconhecidas) pelas grandes potências internacionais. Ora que melhor para este propósito do que a ascensão de uma princesa de Avis ao trono imperial dos Habsburgos? Não proporcionava um casamento imperial uma oportunidade única para consolidar o prestígio internacional da casa de Avis e a segurança externa do reino? Sem dúvida que sim!

Com este matrimónio, Portugal ganhava prestígio entre as casas reinantes da Europa de Quatrocentos. E quanto maior e mais prodigioso fosse o espectáculo de poder resultante do casamento, tanto melhor para os promotores envolvidos (leia-se os monarcas e os reinos). O grande objectivo de $\mathrm{D}$. Afonso $\mathrm{V}$ era que o casamento se transformasse numa ocasião única de afirmação e de triunfo, ou seja, de internacionalização da monarquia portuguesa.

Compreende-se, por tudo isto, a ousada, mas inequivocamente firme e convicta, jogada de D. Afonso V no tabuleiro da diplomacia e da política internacional de alianças. Ousada, e até perigosa, nem que fosse pelo facto

\footnotetext{
8 Idem, ibidem, p. 129.

9 Idem, ibidem, p. 131.
} 
de envolver uma despesa e uma dívida tão grandes que quase arruínam as finanças públicas. De tal forma que o rei, ainda no decurso de 1451 e contrariando a tendência da sua política interna, se decidiu de motu proprio a convocar Cortes em Santarém, para "prover a ajuda financeira que propiciasse os elevadíssimos custos do casamento [e do dote] de D. Leonor com o imperador Frederico III." 10

Podemos (e devemos), enfim, colocar a política de casamentos afonsina, e em particular este matrimónio (cuja forma como é preparado e conduzido indicia uma longa reflexão e uma programação cuidada), no quadro mais geral de uma vasta operação de propaganda política ao serviço da coroa de Portugal, iniciada logo em 1385 e que visava, em última instância, a mitificação da família de Avis: “(...) quando olhamos para estes anos, nos apercebemos de que houve um fio condutor, uma inteligência política empenhada em construir uma imagem mítica da dinastia de Avis e que começa logo pelo fundador, D. João I, e pela esposa, continuando depois para os filhos (e, mais tarde, para os netos), quase sacralizando esta família para a utilizar como exemplo ao serviço da educação de um reino."11

A comitiva de acompanhamento da infanta D. Leonor a Itália era dirigida por João Fernandes da Silveira ${ }^{12}$ (c. 1420-1484) e por Lopo de Almeida, primeiro conde de Abrantes e figura de destaque pela ascensão que então conhecia na corte portuguesa.

Por sua iniciativa ou por incumbência do soberano, Lopo de Almeida enviou a D. Afonso V quatro cartas (ou talvez mais, não sabemos) em que lhe dá notícia dos acontecimentos que marcaram a viagem, bem como da forma como a comitiva foi recebida: a primeira de Siena (Fevereiro de 1452),

${ }^{10}$ Saul António Gomes, D. Afonso V, Rio de Mouro, Temas e Debates, 2009, p. 89.

${ }^{11}$ Idem, ibidem, p. 292.

${ }^{12}$ À data da partida de Portugal da comitiva de acompanhamento da infanta D. Leonor com destino a Itália (1451), já o doutor em leis João Fernandes da Silveira ocupava os cargos de Chanceler da Casa do Cível de Lisboa, regedor da Casa da Suplicação e membro do Conselho Real. Em 1473, D. Afonso V nomeou-o escrivão da puridade, chanceler-mor e vedor da sua Fazenda. Cargos que lhe garantiam uma extrema proximidade ao monarca. Dois anos mais tarde, em 1475, pelos serviços prestados à Coroa na qualidade de alto funcionário régio, em particular como embaixador, o rei concede-lhe o título de barão de Alvito, com direito de transmissão aos seus descendentes. Foi este, aliás, o primeiro título de barão que se concedeu em Portugal. 
Fig. 1 - O encontro entre Frederico III e D. Leonor ocorreu em Siena, em cuja catedral existe um precioso registo iconográfico. Trata-se do famoso fresco do pintor Benardino di Betto, dito o Pintoricchio (1454-1513), no qual se encontra representado, em primeiro plano, o bispo de Siena (Enea Sílvio Piccolomini, mais tarde papa com o nome de Pio II) com os paramentos solenes, acolhendo os noivos.

[in Duomo di Siena]

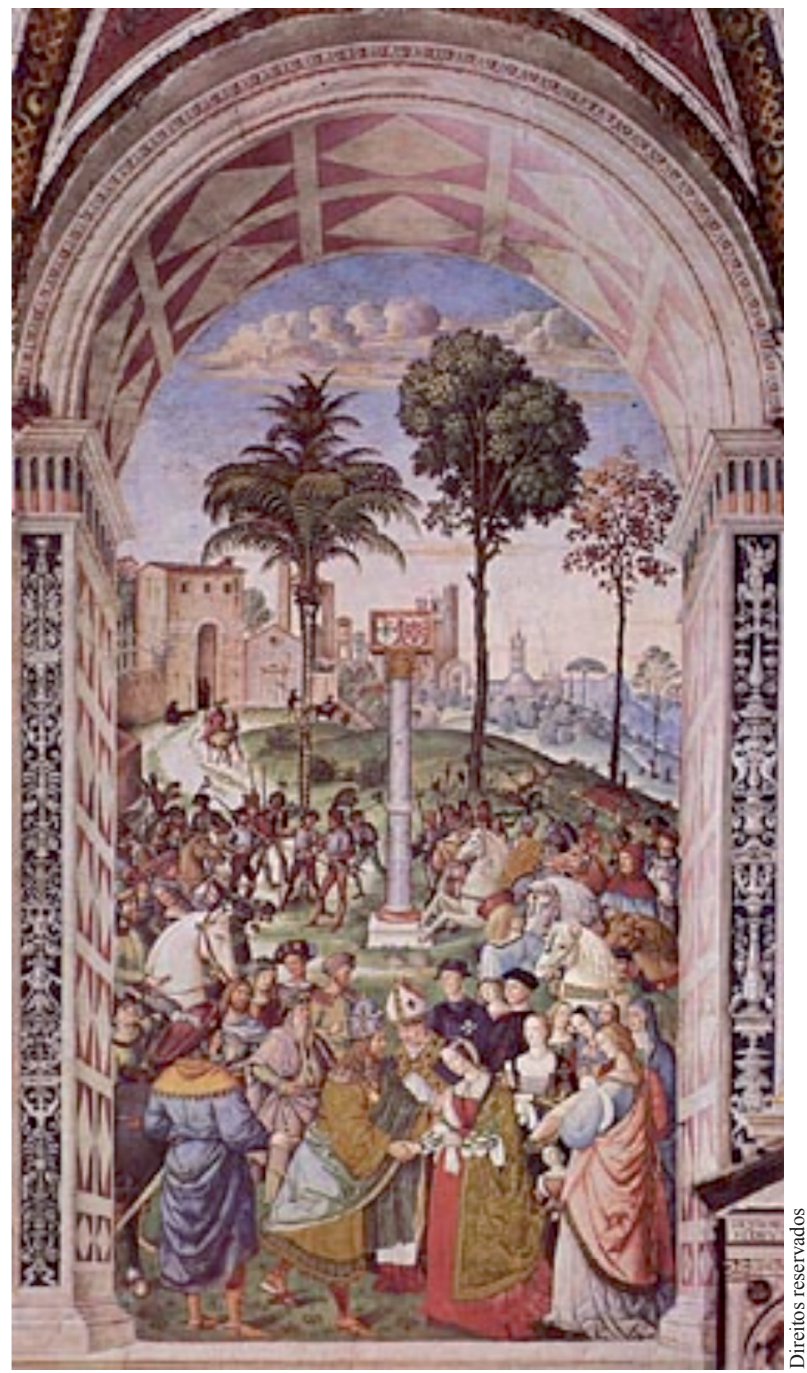


a segunda de Roma (Março), a terceira de Nápoles (Abril) e a quarta (Maio) de um porto algures no Adriático.

O exíguo corpus epistolar de Lopo de Almeida teve apreciável recepção literária, a avaliar pelas cópias que circularam e que deixaram vestígios nos manuscritos que chegaram até nós ${ }^{13}$.

De salientar, no entanto, é que o valor das cartas não reside tanto na vertente literária, mas antes na vivacidade do autor, que não pretende ser sereno ou lógico, mas sim descritivo e emotivo. Sente-se a cada frase a inquietação pessoal e o desassossego. É um estilo temperamental e instintivo, em que a ordem psicológica triunfa constantemente sobre a ordem lógica. Denota-se, enfim, uma acentuada pessoalidade, que passando ao lado dos recursos habituais da expressão literária, se afirma simples mas extraordinariamente enérgica ${ }^{14}$.

O facto de o embaixador concentrar toda a sua atenção na acção, bem como na descrição das cerimónias (onde dois dos tópicos preferidos são o vestuário e os objectos utilizados) e do comportamento dos intervenientes, faz de tais escritos uma fonte de inegável valor histórico-antropológico.

A visão do Outro presente nas Cartas é essencialmente a visão dos europeus setentrionais, mais especificamente os alemães. Exceptuam-se, naturalmente, os franceses e os ingleses, cuja influência na corte portuguesa era vasta e profunda, sobretudo no caso destes últimos por intermédio da rainha Filipa de Lencastre (1359-1415): "Nom tomem porem os vossos oficiaes daqui ousadia, porque estes homens são barbaros e bestas, dos quaes diz o Profeta quorum Deus venter est, mas tomem do bom servir dos vossos Reynos e dos de Ingraterra e de França, que são Reynos de homens e não de bestas." 15; "E certamente, Senhor, nom poderá cuidar que portugueses estavam em tal ponto com os das outras partes, e louvo muito a Deos por me fazer ver isto, porque até agora vejo que sam reyes de quantos cá vy, assim de parecer como de gentileza e esto em tanta differença delles aos

${ }^{13}$ Cf. Manuel Simões, "O panegírico de Portugal nas 'Cartas de Itália', de Lopo d'Almeida" in Studi di iberistica in memoria di Albert Boscolo, Giuseppe Bellini (a cura di), Roma, Bulzoni Editore, 1989, pp. 211-218.

${ }^{14}$ Cf. Rodrigues Lapa, "Prefácio" in Lopo de Almeida, Cartas de Itália, Rodrigues Lapa (ed.), Lisboa, Imprensa Nacional, 1935, pp. V-XIX.

${ }^{15}$ Lopo de Almeida, Cartas de Itália, op. cit., p. 19 [Carta segunda]. 
que vejo, que bem creo que, se todos chegaramos a França assim como a Pisa, acharamo-nos iguaes com os de lá (...)."

Importante também é a referência à corte napolitana, cujos habitantes aragoneses são muito apreciados pelo autor devido à sua generosidade $\mathrm{e}$ nobreza de comportamento.

De reter como nuclear é que todas as apreciações do Outro europeu são sempre realizadas através de uma análise comparativa com os portugueses, apresentados pelo autor como inequivocamente superiores, em todo e qualquer aspecto; ao passo que os alemães são sempre rebaixados: "e todos tem escandalo com os alemães por tão mal tratarem quanto bem lhes cá mandastes." 17

O sistema referencial de Lopo de Almeida contempla, assim, dois níveis de apreensão antitéticos, opondo em primeiro lugar portugueses e alemães; e, num segundo momento, os súbditos do rei de Aragão na corte de Nápoles em contraste com os alemães e os portugueses (estes constituem o verdadeiro alicerce do sistema de avaliação do Outro do autor). Destes confrontos, como se referiu, saem aclamados os portugueses, sempre merecedores de todos os elogios ${ }^{18}$ : "Senhor, isto digo assy pelo meudo, como quem o vio; e sabede, Senhor, que o Papa ama todolos vossos, como se fossem seus e assi no-lo deu a entender e nos mandava pôr nos mais honrados lugares, depois de bispos e condes; e soomente hum alemam não mandava assentar onde nós estavamos, nem outrem em lugar honrado, semelhante ao nosso; e assy se disse a missa per hum cardeal." 19

O problema da avaliação do Outro surge aqui de forma plena, pois o conhecimento desse Outro (e do Eu) é sempre obtido através de um raciocínio analógico: "conheço o outro por analogia comigo" (afinal, a comunicação interpessoal assenta fundamentalmente no diálogo que salvaguarda o Eu e o Tu como sujeitos, como pessoas).

No entanto, este raciocínio analógico tem dois patamares. Um superficial e outro mais profundo e complexo. O texto de Lopo de Almeida fica-se pelo primeiro, ou seja, o conhecimento do Outro europeu assenta mais na

\footnotetext{
${ }^{16}$ Idem, ibidem, pp. 25-26 [Carta terceira].

${ }^{17}$ Idem, ibidem, p. 13 [Carta primeira].

${ }^{18}$ Cf. Manuel Simões, op. cit..

${ }^{19}$ Lopo de Almeida, Cartas de Itália, op. cit., p. 11 [Carta segunda].
} 
comunicação espontânea, na dualidade simpatia/antipatia e na intuição do que no conhecimento reflexivo, isto é, na análise profunda dos seus comportamentos $^{20}$.

Como se nota no texto, tudo surge à flor da pele. O desdém pelos alemães é claramente sensitivo. Daí ao estado de conflito, rivalidade e predomínio de um sobre o outro vai um pequeno passo, como aliás se pode verificar nas expressões do autor.

O "portuguesismo" exagerado de Lopo de Almeida atinge proporções verdadeiramente hiperbólicas, mas não deixa de ser um facto essencial. Por um lado, e antes de tudo, devido a tratar-se de um criado que zelosamente serve o seu rei, o que implica uma retórica do discurso, isto é, uma adequação, que não pode ser ignorada (nesta medida, a depreciação do Outro é, em primeiro lugar, para melhor exaltar e incensar o $E u$ - através do rei que se serve). Por outro lado, porque expressa bem o rumo da civilização portuguesa de então, toda concentrada no périplo dos Descobrimentos e na acção militarista além-mar. Com efeito, as suas palavras funcionam como um espelho do espírito expansionista português de Quatrocentos ${ }^{21}$ : “o milhor Rey do mundo, a milhor terra do mundo, milhores homens de mundo sam os de Portugal." 22 E noutro momento dirá: "Senhor, (...) todo he vosso quanto fizeram e mostraram, porque, com qualquer cousa que lhe vejam trazer ou fazer, nom dizem senão: 'muito bem faça Deos ao Rey que tal gente tem; e certamente nisto mostra bem quem he.' Assim, Senhor, que todo he vosso." ${ }^{23}$

Fundamental, nunca é demais salientar, é não esquecer que este discurso hiperbólico é sempre pronunciado em reacção ao frio e bárbaro comportamento dos alemães. Ele o diz expressamente, aludindo aos "desaviamentos

${ }^{20}$ Cf. Ana Paula Menino Avelar, Figurações da alteridade na cronística da Expansão, Lisboa, Universidade Aberta, 2003, pp. 117-168 e 185-190; idem, Visões do Oriente: formas de sentir no Portugal de quinhentos, Lisboa, Colibri, 2003, pp. 82-83, 149-176 e 273-280; Helena Carvalhão Buescu, Incidências do olhar: percepção e representação, Lisboa, Editorial Caminho, 1990, pp. 71-77; idem (ed.), Narrativas da Modernidade: a Construção do Outro, Lisboa, Colibri, 2001, pp. 81-86 e 92-94.

${ }^{21}$ Cf. Rodrigues Lapa, "Prefácio" in Lopo de Almeida, Cartas de Itália, op. cit., pp. V-XIX.

${ }^{22}$ Lopo de Almeida, Cartas de Itália, op. cit., p. 5 [Carta primeira].

${ }^{23}$ Idem, ibidem, p. 26 [Carta terceira]. 
e bestearias" daqueles homens "barbaros": “( ...) a dita Senhora (...) foi-se a hum cadafalso, que estava feito, e com ella El-Rey d'Ungria, e assentarão-se em hum banco com hua alcatifa, sem o veador ter cuidado de prover onde avia de estar, nem lhe fazer poer aly hum pano de brocado ou de seda, de que tantos lhe destes; e assy outros desaviamentos e bestearias, que cada ora fazem como canarios." ${ }^{24}$

Lopo de Almeida supera aqui a especificidade da imagem do alemão para o enquadrar no código cultural que nesta época está disponível na corte régia portuguesa. É esta a forma escolhida para tornar inteligível e avaliar o Outro que se lhe apresenta ao olhar.

Por outras palavras, os referentes culturais de Lopo de Almeida constituem-se aqui como um código de que fazem parte classificações e valores diversos, nomeadamente os da cortesia. E é com base neste código referencial que o autor valoriza ou desvaloriza o Outro europeu ${ }^{25}$.

Sendo o imperador o líder e o espelho do seu povo, ele congrega em si todos os elementos negativos deste. Veja-se, logo na primeira carta, a cena passada em Florença, em que o Imperador regateia com os homens de Cosmo de Medicis um damasquim de brocado. Toda a descrição revela perfeitamente a sórdida avareza do monarca e todo o desdém do fidalgo português: "Juro-vos, Senhor, que ante queria ser Rey de Castella, que elle é muito escasso, sem nenhuma comparação, e avarento, e vereis que fez: elle queria comprar em Florença hum damasquim de brocado branco de Cosmo de Medices e mando-o vir pera o ver e esteve regatando com os homens do dito Cosmo grande pedaço, de guisa que se não avierão e foram-se com o pano; a cabo de espaço, mandou-lhe dizer que aquelles seus homens estavão muito caros com aquelle pano, que lhe rogava que lhes mandasse que lhe

${ }^{24}$ Idem, ibidem, p. 9 [Carta segunda].

${ }^{25}$ Cf. António Avelino Neves Casaca, O olhar do outro na Crónica do Conde D. Pedro de Meneses, Texto policopiado, Tese Mestrado Interdisciplinar em Estudos Portugueses, Lisboa, Universidade Aberta, 2000, pp. 96-118; Jacques Le Goff, História e Memória, vol. II - Memória, Lisboa, Edições 70, 2000, pp. 193-231; José da Silva Horta, “A imagem do Africano pelos portugueses antes dos contactos" in $O$ Confronto do Olhar, O Encontro dos Povos na Época das Navegações Portuguesas, António Luís Ferronha (coord.), Lisboa, Editorial Caminho, 1991, pp. 43-69; idem, "A representação do africano na literatura de viagens, do Senegal à Serra Leoa: 1453-1508" in Mare Liberum, ${ }^{\circ}$ 2, Lisboa, CNCDP, 1991, pp. 209-338. 
fizessem delle bom preço; e o dito Cosmo, que jazia doente, disse aos seus feitores que bem sabia elle o mercado que o Emperador queria delle, e mandou que lhe levassem de graça; e elle que o tomou e pesou-lhe com o pouco! A nenhum destes vossos fidalgos, que se expidirão delle, nam deu nem hum soo ducado, nem hum pam, nem a mim com elles." 26

Outra crítica directa a Frederico III e que revela igualmente o profundo sentimento ou atitude (orgulhosa) de desprezo do autor para com o imperador reside na fraqueza do seu carácter, pois nunca toma uma decisão, por muito leve que seja, sem consultar vários do seu conselho: "nunca cuidei de ver homem tam pouco estar em seus pees, que soomente a dizer-lhe hum homem que se quer ir com sua mercê, nom lhe dá reposta senão que primeiro fale com três ou coatro do Conselho." ${ }^{27}$

Sempre que pode, Lopo de Almeida coloca em evidência a diferença de temperamentos entre Frederico e D. Leonor, sendo ele desconfiado, calculador e brutal na expressão e nas maneiras. Enfim, medíocre e bastante inferior à graciosa princesa lusa: "A dita Senhora ia vestida na cota de cramesim, que lhe destes, e na opa de brocado pardo, e bem toucada com huma crespina rica e hum rance em cima e cengido hum tecido de brocado branco, dos seis que lhe cá dei per vosso mandado; e, alem de ir muito fermosa, é bem de louvar por sua segurança e boa contenença; e foi muito prasmado o Emperador, porque a mandou vir antre estes dous duques; e todos tem escandalo com os alemães por tão mal tratarem quanto bem lhes cá mandastes." 28

Mas o que mais impressiona o embaixador português é a falta de ordem, o desrespeito das normas sociais, que ia dos nossos costumes para os dos alemães, muito mais livres e brutais: "Vossa Irmãa estava em sua pousada e vierão a ella pera a levar dous duques, per mandado do Emperador; e a nós pareceo mal, a saber, a Luis Gonçalves e a mim, não mandar o Emperador a El-Rey d'Ungria e ao Duque, seu irmão. E a dita Senhora mandou dizer ao Emperador a maneira que se tinha em vossos Reynos em semelhantes casos e fomos-lho dizer aa Igreja, dizendo-lhe que, quando ella ia fora em

\footnotetext{
${ }^{26}$ Lopo de Almeida, Cartas de Itália, op. cit., p. 4 [Carta primeira].

${ }^{27}$ Idem, ibidem, pp. 3-4 [Carta primeira].

${ }^{28}$ Idem, ibidem, pp. 12-13 [Carta segunda].
} 
vossos Reynos, sempre ião com ella os Infantes e assy todos, posto que fosse o mais honrado, e que, depois que fora desposada com elle, sempre fora acompanhada de vós e de vosso irmão e tios pera qualquer parte que ia fora de casa, e que alem disto era usança em vossas terras de se fazer grandes honras aas noivas, o dia das vodas, e que vós levaveis a molher de hum fidalgo de vossa casa de huma parte pera a outra, o tal dia, e que portanto lhe parecia que devia mandar ao dito Rey d'Ungria e ao Duque, seu irmão delle, dito Senhor, por ella; e que esto dizia ella por serviço delle, porque tudo o que se a ella fizesse seria delle; e que considerasse quanto parecia estranho a quantos estrangeiros ahy estavam, se lhe vissem fazer o contrario do que sabem que em suas terras se faz (...). E o dito Senhor ouvio esto antre três ou coatro, antre os quaes estava o seu mestre da camara, que o rege, o qual respondeo por mandado delle e disse que ella não ouvesse dello desprazer, que fora assy ordenado, e assy outras razões frias, e que ella viesse, que cá na Igreja a acompanharia El-Rey d'Ungria." 29

Com efeito, a desordem, a falta de brilho e a pobreza de tal comitiva, são explicadas pela extrema avareza do Imperador e pelas condições especiais de abandono em que ele se deslocou a Itália. Mas, na realidade, tal "mediocridade" justifica-se em grande parte pela crise interna que o imperador, à época, tinha em mãos e que envolvia numa grave conspiração alguns dos principais senhores austríacos, liderados por Ulrich Eizinger ${ }^{30}$.

Plena de ironia, humor e intenção pessoal, a narração da ceia - da responsabilidade dos alemães - nos paços de S. João de Latrão, que se seguiu à cerimónia da confirmação do casamento e da coroação do imperador, é paradigmática a este respeito. Em particular na descrição da mesa do imperador, o embaixador português chega mesmo a ser profundamente satírico: "E o Doutor e eu fomos ver como estava a sala pera comer aparelhada e achamos a mesa posta pera elle [o imperador], que lhe não

${ }^{29}$ Idem, ibidem, pp. 7-8 [Carta segunda].

${ }^{30}$ Para um maior aprofundamento desta temática vide Adam Wandruszka, The House of Habsburg: Six Hundred Years of a European Dynasty, Westport (Connecticut), Greenwood Press, 1975; Geoffrey Barraclough, The Origins of Modern Germany, Oxford, B. Blackwell, 1947; Michael Hughes, Early Modern Germany, 1477-1806, Philadelphia, University of Pennsylvania Press, 1992; Paul-Joachim Heinig, "How large was the Court of Emperor Frederick III?" in Princes Patronage and the Nobility: The Court at the Beginning of the Modern Age, cc. 1450-1650, New York, Oxford University Press, 1991, pp. 139-156. 
Fig. 2 - Encontro entre Frederico III e D. Leonor. [pormenor do fresco do pintor Benardino di Betto, dito o Pintoricchio (1454-1513), in Duomo di Siena]

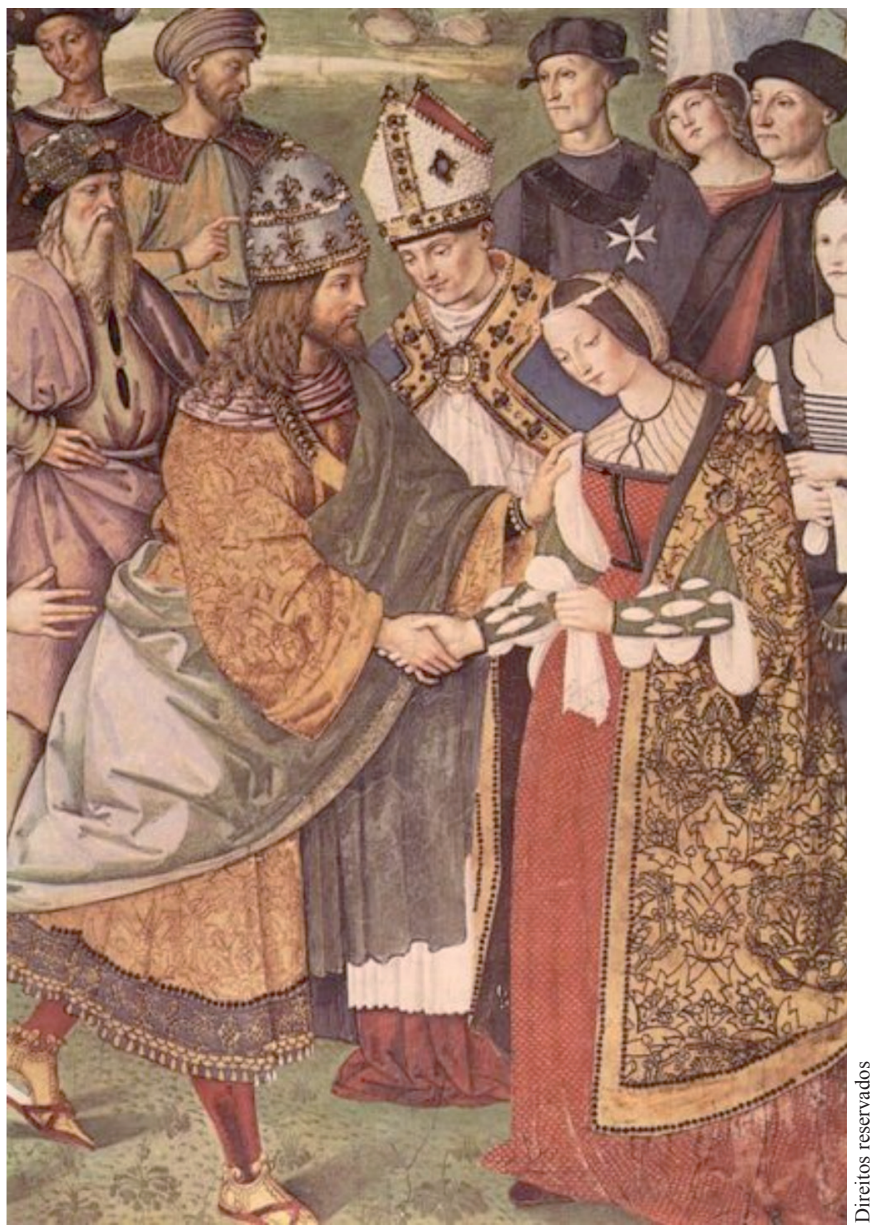

chegavam as toalhas ao cabo e ficava descoberto da mesa acerca de dous palmos, e outras toalhas estreitas pelas bordas de hua parte e da outra da mesa pera se alimparem; e poserom aa primeira coatro ou cinco coutos de pães de cera por castiçaes na dita mesa, e parece que viram que não estava como compria e trouxeram hum castiçal de prata, que parecia de ferro, e tirarom os que estavam nos pães.

As outras mesas estavom postas com toalhas e candeas em pães e no cabo da casa estava hua mesa na altura das outras, na qual estava a prata 
per que aviam de beber, pouca e mal corregida; e a cabo de mea hora veo o Emperador e ante elle hum homem com duas tochas em hua mam, que parecia hua soo, e chegou diante da mesa e com elle El-Rey de Ungria e Dom James, seu mestre da câmara, e outros senhores alemães e lavarão em pee, em tal maneira que não podemos enxergar se lavarão ou não; (...) e veo a vianda em grandes dous bacios, em maneira de Castela, e comerom a commum todos mesturados com elle, de guisa que todos comião nos ditos dous bacios; e cada hum tinha trinchos de pao ante si.

Na mesa nam era posto bancal senão as toalhas sobre a tavoa, e parecia ella bem descoberta daquella parte onde nom chegavam as toalhas; e nos bancos tam pouco avia bancaes, salvo onde sya o Emperador huma almofada de cramesim avelutado pera elle.

Nas outras mesas se assentarom bispos, condes e prelados e todos os outros fidalgos e toda a outra gente a feixes e molhos, como em voda; e o arroido da gente desbaratava o de João Vaaz.

Ante o vinho nem ante as iguarias nom vinham tochas aa mesa nem porteiro que fizesse fazer logar; tras a mesa do Emperador erom armadas duas cobricamas de ras d'arvoredo, sem nenhum pano d'estado nem outro nenhum pano nem sarjas per toda a salla." ${ }^{31}$

O olhar atento e perspicaz do embaixador, portador dos seus próprios padrões de comportamento social, condiciona a sua apreciação, quase sempre depreciativa. Dito de outra forma, estamos perante uma avaliação antropológica que funciona consoante o Outro, na imagem que dele o autor constrói, se aproxima ou afasta do padrão que a priori definiu para si mesmo e de que não abdica ${ }^{32}$.

Neste quadro, pela pertinência enquanto notável exemplo, mais uma vez citamos as seguintes palavras do embaixador luso: "Nom tomem porem os vossos oficiaes daqui ousadia, porque estes homens são barbaros e bestas,

${ }^{31}$ Lopo de Almeida, Cartas de Itália, op. cit., pp. 17-19 [Carta segunda].

32 Cf. Claude Lévi-Strauss, Raça e História, Lisboa, Editorial Presença, 1980, pp. 19-28; Edward W. Said, Orientalismo. Representações Ocidentais do Oriente, Lisboa, Livros Cotovia, 2004, pp. 5-31; Luís Filipe Barreto, Descobrimentos e Renascimento: Formas de Ser e Pensar nos Séculos XV e XVI, Lisboa, INCM, 1983, pp. 127-184; Peter Burke, Formas de Historia Cultural, Madrid, Alianza Editorial, 2006, pp. 241-264; Tzvetan Todorov, A conquista da América: a questão do outro, Lisboa, Litoral Edições, 1990, pp. 11-65, 227-246 e 297-308. 
dos quaes diz o Profeta quorum Deus venter est, mas tomem do bom servir dos vossos Reynos e dos de Ingraterra e de França, que são Reynos de homens e não de bestas." 33

Daqui podemos depreender que é pela aparição do Outro, que tenho a possibilidade de fazer um juízo sobre mim como sobre um objecto. E no discurso de Lopo de Almeida, como temos vindo a verificar, o Outro está "sempre já aí,, originariamente co-presente ao Eu. Em suma, sem esta coexistência do Eu com o Outro, as Cartas perdem todo o seu sentido e riqueza.

O alemão é, no discurso de Lopo de Almeida, um objecto de valores que o qualificam sem que possa agir de forma efectiva sobre essa qualificação, pois ela surge logo a priori. Assim, as referências do autor colocam em evidência que ser olhado é estar sujeito às apreciações do Outro. É sentir-se como objecto desconhecido de apreciações várias, em particular as apreciações de valor.

Regressando ao texto, a dado momento, a própria imperatriz, superior no seu encanto e delicadeza de figura, teve a ousadia de sugerir o código de comportamento protocolar, o que, na perspectiva do autor, só revela a fraqueza dos alemães e em particular do Imperador: "Vossa Irmãa estava em sua camara este seram, esperando que o Emperador fosse lá; e elle mandou por ella dous condes, que se fosse aa camara delle; e ella nom quis e passarom-se sobre esto muitas embaixadas per cinco ou seis vezes, segundo me disserom, até que elle veo por ella e disse-lhe que lhe prazia que ella fosse folgar a sua camara por essa noute e levou-a polla mam; e, tanto que entrou, lançarom-na na cama e elle com ella nom sabemos que foi lá. Assim, Senhor, que a consumaçam do matrimonio foi a noute de ante Domingo de Pascoella." ${ }^{34}$

Para Lopo de Almeida este é um dos grandes motivos para avançar a bestialidade e as profundas limitações dos alemães, que efectivamente não mereciam tal figura.

\footnotetext{
${ }^{33}$ Lopo de Almeida, Cartas de Itália, op. cit., p. 19 [Carta segunda].

${ }^{34}$ Idem, ibidem, p. 29 [Carta terceira].
} 
É o que novamente refere, já em momento de despedida da corte de Nápoles: "E toda a gente, El-rey e donas não se fartão de a ver e lamentar por a ver vir tam longe e antre tal gente como alemães e lograda por tal pessoa." 35

Por contraste com os alemães, Lopo de Almeida realça o comportamento da nobreza aragonesa na corte de Nápoles, que tão bem recebe a comitiva portuguesa: "e tanto que vossa Irmãa chegou a terra d'El-Rey de Aragão, tornou-se o sobredito vice-camaralengo do Papa e ali achou a Mossem Vasco e certos officiaes do dito Rey, os quaes a fezerom apousentar por todolos lugares por onde veo, dando os mantimentos pera toda a gente sem dinheiro e não consentindo que pagassemos nem as ferragens das bestas; estavam pelas ruas dos lugares mesas postas per onde vinhamos e comia quem queria e fontes feitas de vinho; em algumas partes nem consentiam que pagassemos calçado, mas tudo era mandado que nos dessem sem dinheiro nem outra nenhuma cousa que quisessemos comprar; e muito mais compridamente se fez isto ao Emperador e aa dita Senhora e não se dava senão quanto homem queria. E certifico-vos, Senhor, que pera minha casa davão pera cada dia passante de huma quarta de medir pão de confeitos, e se mais queria mais davão." ${ }^{36}$

Para dar a ver a forma positiva como vê a corte napolitana do rei de Aragão, Lopo de Almeida chega ao ponto de não hesitar em aí deixar o seu próprio sobrinho, a pedido do monarca: "e acabando, mandarom bailar meu sobrinho com Briatiz Lopes o bailo mourisco e depois o villam, e espantou-se El-Rey do seu bailar e fez-me entender que lhe prazeria que ficasse alguns dias com elle, dizendo que os vossos erom seus e os seus vossos, e que elle se queria agora servir delle alguns dias e disse que vollo mandaria. Eu the disse que, conhecendo eu que vós averieis prazer de se elle servir dos vossos, me prazia que elle ficasse. Esto fiz, porque entendi que vos nom desprazeria dello, e quando de cá for irá mais apurado e ensaiado pera vos servir; assy, Senhor, que por estes fundamentos o leixei cá." 37

Neste passo é crucial verificar a importância atribuída por Lopo de Almeida aos costumes cortesãos, ausentes da nobreza alemã e plenos na

\footnotetext{
${ }^{35}$ Idem, ibidem, p. 33 [Carta quarta].

${ }^{36}$ Idem, ibidem, p. 22 [Carta terceira].

${ }^{37}$ Idem, ibidem, pp. 27-28 [Carta terceira].
} 
corte de Nápoles. Pormenores essenciais da etiqueta cortesã, como a dança, o requinte e a gentileza dos hábitos, ou a maneira de vestir, são altamente valorizados pelo embaixador luso, que ao longo das cartas nunca deixa de destacar - sempre por comparação com os alemães - o cultivo de uma cultura de aparato. Ora, isto é profundamente revelador da ambiência que predominava na corte régia portuguesa.

Em contacto com civilizações diferentes - a alemã, a italiana e a aragonesa -, Lopo de Almeida compara todos os que vê a personagens do seu país. Facto que não se explica apenas pela circunstância de fornecer ao rei, o efectivo destinatário das cartas, fáceis e inequívocos termos de comparação. Na verdade, no processo de construção da visão do Outro, a comparação com o português (ou seja, o Eu) impõe-se necessariamente como referente cultural. É o incógnito João Vaz dotado de grande voz. É o príncipe de Aragão que se assemelha ao moço de câmara Gomes Pinto, reparando contudo que o nariz daquele não era tão mal feito quanto o deste. É ainda a pequenez de corpo e a cortesia discreta deste mesmo príncipe de Aragão que lembra a de João de Meneses, um apaixonado da princesa, que, vendo-a roubada se tornou frade ${ }^{38}$ : "A esta cidade veo Sancha de Bairros fazer reverença aa dita Senhora, e com ella seu marido, hum bom cavaleiro, que chamavão Mossem de Aveiro; e ambos vierom acompanhando a dita Senhora; e, chegando a Bresa, veo recebe-la o Principe, filho de El-Rey, vestido em hum mantão de veludo preto forrado de martas, em cima de huma mulla, e com elle muito poucos; parece-se proprio com Gomes Pinto, vosso moço da camara, porem o nariz nom he tão mal feito, pequeno de corpo como João de Meneses, cortês e pouco solto." 39

Outro bom exemplo é aquele em que, já na abundante e rica corte de Nápoles, o autor evoca o apetite voraz do português Fernão Cerveira, que proclamava a viva voz que três patos lhe chegavam bem antes de deitar: "Senhor (...) este dia, acabadas as justas, forom cear e, acabada a cea, vierom todos pera vossa Irmãa e levaram-na pera a casa do Emperador e andarom dançando em sua sala casi huma ora; e veo colaçam moor que a

${ }^{38}$ Cf. Rodrigues Lapa, "Prefácio" in Lopo de Almeida, Cartas de Itália, op. cit., pp. V-XIX.

${ }^{39}$ Lopo de Almeida, Cartas de Itália, op. cit., pp. 22-23 [Carta terceira]. 
de Fernam Cerveira, que com três patos dizia que se fartaria mui bem e lançaria na cama." ${ }^{\prime \prime}$

Por fim, merece igualmente destaque a situação em que Lopo de Almeida refere os dois miseráveis rocins de dois pobres duques alemães que the trouxeram à memória os arreios dum tal Afonso Mendes: "E quando vossa Irmãa partio pera embarcar pera o Golfão, vierom com a dita Senhora dous duques, cada hum de mil e quinhentos ducados de renda, em cima de senhos rocins magros, com goarnimentos de couro vermelho, piores que os de Affonso Mendes, a que se despacharom as cobertas em Mayorga, e com elles até quinze de cavalo e senhos sacomanos rotos por moços de estribeira." ${ }^{41}$

Noutra vertente, e mais uma vez fazendo recurso do método comparativo com a sua nação de origem, salientamos que o autor, apesar de "bom profeta", não revela a sensibilidade necessária para avaliar devidamente a civilização italiana coeva. É isso que nos indica a sua afirmação do final da primeira carta: "E, segundo a desposição desta terra, a meu fraco entender, se aqui viesse hum Emperador rijo, toma-la-hia toda sem nenhua detença, moormente que com a cativeza da gente della, nom andam na guerra senom por aver proveito, sem vontade de pelejar nem matar, e moormente se o Emperador, que esto houvesse de fazer, tivesse dos cabililouros d'antre Tejo e Odiana"42.

Mal sabia o viajante luso, que dentro em breve iriam ter início as chamadas Guerras de Itália (1494-1559), e que os portugueses não seriam os grandes protagonistas do conflito. Ao contrário, daí surgiria a nova grande potência continental e marítima: precisamente a vizinha Espanha ${ }^{43}$ : "No que diz respeito à Europa 'que domina', ou seja, que está no centro dos acontecimentos políticos, económicos, culturais, duas potências, neste início do século XVI, disputavam entre si a supremacia neste continente que então se definia para a modernidade. Os anos de 1520-1521 eram particular-

${ }^{40}$ Idem, ibidem, p. 28 [Carta terceira].

${ }^{41}$ Idem, ibidem, p. 34 [Carta quarta].

${ }^{42}$ Idem, ibidem, p. 5 [Carta primeira].

${ }^{43}$ Cf. Ana Isabel Buescu, Catarina de Áustria, Infanta de Tordesilhas, Rainha de Portugal, Lisboa, Esfera dos Livros, 2007, pp. 103-142; idem, D. João III, Rio de Mouro, Temas e Debates, 2008, pp. 102-108; John Rigby Hale, A Civilização Europeia no Renascimento, Lisboa, Editorial Presença, 2000, pp. 65-142; V. H. H. Green, Renascimento e Reforma, Lisboa, Dom Quixote, 1991, pp. 67-78, 103-112 e 145-150. 
mente significativos do novo patamar em que se definia este confronto. Depois de uma primeira fase das chamadas Guerras de Itália (1494-1559) que terminara, em 1516, com a vitória de Francisco I após a brilhante vitória de Marignan no ano anterior, o confronto entre a França e a Espanha entrava numa nova fase, marcada pela eleição imperial de 1519. A eleição de Carlos V, I de Espanha, como imperador, conseguida em condições difíceis face aos outros candidatos ao trono imperial, Francisco I de França e Henrique VIII de Inglaterra, constituiu, na verdade, um factor decisivo para uma nova correlação de forças entre a França e a Espanha, as duas potências que, dando corpo a uma rivalidade de carácter dinástico e territorial, mas que revestiria também, por parte dos seus dois principais protagonistas, uma dimensão de natureza pessoal, disputaram a hegemonia europeia na primeira metade do século XVI. Durante cerca de quarenta anos, os soberanos das dinastias de Habsburgos e Valois, Carlos V e Francisco I entregaram-se, no cenário de uma Itália culturalmente brilhante mas politicamente fraca, a um confronto tenaz e persistente, pontuado de breves tréguas ocasionadas sobretudo por embaraços de natureza financeira, que culminou, com o Tratado de Cateau Cambrésis, já assinado pelos seus sucessores Henrique II (r.1547-1559) e Filipe II (r. 1556-1598) em 1559, na confirmação da supremacia espanhola sobre a Europa até final do século XVI." ${ }^{44}$

Entretanto, observemos a importância antropológica do termo "cabililouros", que designa aqui um tipo de homem com cabelo louro daquela região do sul de Portugal, entre a qual parecia que se recrutavam bons guerreiros ${ }^{45}$. Passo curioso, pois os alemães são, regra geral, associados ao cabelo louro, facto que não deteve Lopo de Almeida de efectuar uma referência indirecta - mas com evidente marca diferenciadora - à qualidade guerreira dos portugueses em comparação com a dos soldados do imperador que neste contexto só pode ser Frederico III, o que só revela a inevitabilidade do choque civilizacional e a incapacidade do autor para se abrir e dialogar com o Outro.

Afinal, é fundamental distinguir entre a percepção do Outro e o conhecimento do Outro. A primeira, a efectuada por Lopo de Almeida,

\footnotetext{
${ }^{44}$ Ana Isabel Buescu, D. João III, op. cit., pp. 104-105.

${ }^{45}$ Cf. Rodrigues Lapa, "Prefácio" in Lopo de Almeida, Cartas de Itália, op. cit., pp. V-XIX.
} 
é imediata, a segunda marcadamente reflexiva. O resultado é a permanente impossibilidade nas Cartas de compreensão do Outro autêntico, como alteridade, diferença. Razão para tal, a subjectividade que impera e funciona como alicerce ao longo de todo o discurso do embaixador.

Em síntese, pelo seu conteúdo, mas também pelo contexto em que foram produzidas, as quatro cartas enviadas de Itália por Lopo de Almeida ao rei D. Afonso $\mathrm{V}$ constituem um testemunho privilegiado, por um lado, da forma como os portugueses olhavam o Outro europeu - no caso os alemães e os habitantes da Nápoles aragonesa -, e, por outro lado, da forma como se olhavam a si próprios por reacção a esse mesmo Outro europeu, em meados do século XV. Por outras palavras, a coexistência do $E u$ com o Outro constitui a pedra-de-toque e o elemento fundador, quase arquétipo, das Cartas de Itália. É caso para evocar Nietzsche na sua impressiva afirmação de que, "O $T u$ é mais antigo do que o $E u(. .$.$) : é por isso que o homem se afadiga$ ao redor do próximo" 46 .

Sempre perspicaz, e não raras vezes irónico e satírico, Lopo de Almeida fornece retratos ora colectivos, como o dos alemães, ora individuais, como o do imperador Frederico III. De reter é que em caso algum estamos perante retratos frios. Ao contrário, são sempre representações extremamente ricas do ponto de vista do sentimento, da emoção e do elemento humano, inequivocamente aquele que mais entusiasma o autor da narrativa.

Por outro lado, graças aos seus intensos registos epistolares, podemos verificar que a cultura cortesã estava plenamente implantada na corte portuguesa e constituía o grande referente para avaliar o Outro europeu que se encontrava no mesmo patamar social, sobretudo ao nível dos comportamentos.

Com efeito, os usos cortesãos então em voga - a conversação feminina, as preocupações com o vestuário e a dança - são recorrentemente evocados pelo autor, cujas missivas deixam entender o largo prestígio de que estas actividades gozavam junto da nobreza. Naturalmente, trata-se de um prestígio propiciado pela frequência dos meios cortesãos e, sobretudo, da corte régia.

\footnotetext{
${ }^{46}$ Friedrich Nietzsche, Assim Falava Zaratustra, Lisboa, Guimarães Editores, 2007, p. 37.
} 
Local de contactos frequentes da elite laica portuguesa, mais aberta, por diferentes vias, à influência estrangeira (sobretudo inglesa e francesa), a corte assumia-se como local privilegiado de um processo educativo que se reflectia não só no cuidado com o comportamento e o aspecto exterior, mas também numa maior polidez no trato com a mulher, bem como na prática de artes diversas como a dança. Dito de outra forma, a corte desempenha um papel central como foco cultural e, consequentemente, como norteadora da evolução da cultura da nobreza ${ }^{47}$.

Afinal, o convívio cortesão, complementando a preparação física, devia orientar o comportamento do jovem na corte, quer perante os seus pares, quer perante o elemento feminino aí presente. Isto é por demais evidente na passagem das Cartas relativa à corte de Nápoles.

É, pois, neste mundo cultural em mutação, pautado pela definição de novos modelos de comportamento da elite cortesã, que temos de situar as Cartas de Lopo de Almeida e a sua preciosa visão do Outro europeu.

\section{Fontes e Bibliografia}

\section{Fontes impressas}

ALMEIDA, Lopo de, Cartas de Itália, Rodrigues Lapa (ed.), Lisboa, Imprensa Nacional, 1935.

Princesas de Portugal, Contratos Matrimoniais dos Séculos XV e XVI, Aires A. Nascimento (ed.) com a colaboração de Maria Filomena Andrade \& Maria Teresa Rebelo da Silva, Lisboa, Edições Cosmos, 1992.

\footnotetext{
${ }^{47}$ Cf. A. H. de Oliveira Marques, A Sociedade Medieval Portuguesa. Ensaios de vida quotidiana, Lisboa, Sá da Costa, 1974, pp.185-221; António Resende de Oliveira, “"Mais de pedras que de livros': D. Afonso, $4^{\circ}$ Conde de Ourém, e a cultura nobiliárquica do seu tempo" in Actas do Congresso Histórico, D. Afonso, $4^{\circ}$ Conde de Ourém, e a sua época, Carlos Ascenso André (coord.), Ourém, Câmara Municipal de Ourém, 2004, pp. 293-310; Hervé Martin, Mentalités Médiévales, XIème-XVème Siècle, Paris, Presses Universitaires de France, 1996, pp. 377-398; Jacques Le Goff, História e Memória, vol. I - História, Lisboa, Edições 70, 2000, pp. 141-152 e 191-203; João Gouveia Monteiro, "Orientações da cultura da corte na primeira metade do século XV (a literatura dos Príncipes de Avis)" in Vértice, $2^{\mathrm{a}}$ série, $\mathrm{n}^{\mathrm{o}}$ 5, Agosto de 1988, Lisboa, pp. 89-103; Rita Costa Gomes, A Corte dos Reis de Portugal no Final da Idade Média, Lisboa, Difel, 1995, pp. 46-62 e 295-320.
} 


\section{Estudos}

AVELAR, Ana Paula Menino, Figurações da alteridade na cronística da Expansão, Lisboa, Universidade Aberta, 2003.

- Visões do Oriente: formas de sentir no Portugal de quinhentos, Lisboa, Colibri, 2003.

BARRETO, Luís Filipe, Descobrimentos e Renascimento: Formas de Ser e Pensar nos Séculos XV e XVI, Lisboa, INCM, 1983.

BUESCU, Ana Isabel, Catarina de Áustria, Infanta de Tordesilhas, Rainha de Portugal, Lisboa, Esfera dos Livros, 2007.

-, D. João III, Rio de Mouro, Temas e Debates, 2008.

BUESCU, Helena Carvalhão, Incidências do olhar: percepção e representação, Lisboa, Editorial Caminho, 1990.

- (ed.), Narrativas da Modernidade: a Construção do Outro, Lisboa, Colibri, 2001.

BURKE, Peter, Formas de Historia Cultural, Madrid, Alianza Editorial, 2006.

CASACA, António Avelino Neves, O olhar do outro na Crónica do Conde D. Pedro de Meneses, Texto policopiado, Tese Mestrado Interdisciplinar em Estudos Portugueses, Lisboa, Universidade Aberta, 2000.

DELUMEAU, Jean, A Civilização do Renascimento, Lisboa, Edições 70, 2004.

DUARTE, Luís Miguel, D. Duarte, Rio de Mouro, Temas e Debates, 2007.

GOMES, Rita Costa, A Corte dos Reis de Portugal no Final da Idade Média, Lisboa, Difel, 1995.

GOMES, Saul António, D. Afonso V, Rio de Mouro, Temas e Debates, 2009. GREEN, V. H. H., Renascimento e Reforma, Lisboa, Dom Quixote, 1991. HALE, John Rigby, A Civilização Europeia no Renascimento, Lisboa, Editorial Presença, 2000.

HORTA, José da Silva, "A imagem do Africano pelos portugueses antes dos contactos" in O Confronto do Olhar, O Encontro dos Povos na Época das Navegações Portuguesas, António Luís Ferronha (coord.), Lisboa, Editorial Caminho, 1991, pp. 43-69.

—, "A representação do africano na literatura de viagens, do Senegal à Serra Leoa: 1453-1508" in Mare Liberum, n 2, Lisboa, CNCDP, 1991, pp. 209-338. 
LE GOFF, Jacques, História e Memória, 2 vols., Lisboa, Edições 70, 2000. LÉVI-STRAUSS, Claude, Raça e História, Lisboa, Editorial Presença, 1980. MARQUES, A. H. de Oliveira, A Sociedade Medieval Portuguesa. Ensaios de vida quotidiana, Lisboa, Sá da Costa, 1974.

MARTIN, Hervé, Mentalités Médiévales, XIème-XVème Siècle, Paris, Presses Universitaires de France, 1996.

MONTEIRO, João Gouveia, "Orientações da cultura da corte na primeira metade do século XV (a literatura dos Príncipes de Avis)" in Vértice, $2^{\mathrm{a}}$ série, $\mathrm{n}^{\circ}$ 5, Agosto de 1988, Lisboa, pp. 89-103.

OLIVEIRA, António Resende de, "'Mais de pedras que de livros": D. Afonso, $4^{\circ}$ Conde de Ourém, e a cultura nobiliárquica do seu tempo" in Actas do Congresso Histórico, D. Afonso, $4^{\circ}$ Conde de Ourém, e a sua época, Carlos Ascenso André (coord.), Ourém, Câmara Municipal de Ourém, 2004, pp. 293-310.

SAID, Edward W., Orientalismo. Representações Ocidentais do Oriente, Lisboa, Livros Cotovia, 2004.

SIMÕES, Manuel, "O panegírico de Portugal nas 'Cartas de Itália', de Lopo d'Almeida" in Studi di iberistica in memoria di Albert Boscolo, Giuseppe Bellini (a cura di), Roma, Bulzoni Editore, 1989, pp. 211-218.

TODOROV, Tzvetan, A conquista da América: a questão do outro, Lisboa, Litoral Edições, 1990. 